\title{
A DENSIDADE SEMÂNTICA DA KATCHANGA E A CRISE DA JURIDICIDADE NO BRASIL
}

Victor Pimenta de Miranda ${ }^{12}$

Recebido em: 15/04/2019

Aprovado em: 06/12/2019

\begin{abstract}
RESUMO
A moldura kelseniana propõe que a interpretação normativa deve ser sistêmica e o ordenamento jurídico deve ser coerente para que exista segurança nas relações sociais. O raciocínio interpretativo para aplicar corretamente uma norma deve encontrar respaldo no próprio ordenamento em que está inserido. Com efeito, a história da "Teoria da Katchanga" serve para metaforizar a dogmática jurídica atual da Suprema Corte brasileira, simbolizando como as decisões forenses e o entendimento dos ministros ("Katchanga Real") mudam as regras do jogo e causam grande insegurança aos cidadãos.
\end{abstract}

Palavras-chave: Segurança jurídica. Teoria Katchanga. Jurisprudência.

\section{INTRODUÇÃO}

O Poder Judiciário foi concebido pelo Estado Democrático de Direito como instituição essencial para a busca da pacificação dos conflitos, a promoção da justiça social e a efetivação dos direitos e garantias fundamentais. O ordenamento jurídico se caracteriza como um sistema normativo harmônico, coerente e sancionador que é regulado pela Constituição Federal de 1988.

Nesse contexto, a importância do presente estudo pode ser evidenciada justamente pelo fato de que a interpretação do direito demonstra ser cada dia mais determinante para a solução dos conflitos. Porém, quase tudo é respondido apenas como probabilidade de algo acontecer, pois a qualquer momento um novo entendimento jurisprudencial pode surgir e mudar os resultados esperados.

\footnotetext{
${ }^{12}$ Mestrando (2019) e Bacharel (2010) em Direito pela PUC Minas. MBA (2017) em Gestão Financeira e Controladoria pelo SENAC/MG. Especialista (2012) em Direito Tributário pela Faculdade Milton Campo. Advogado.
} 
O presente estudo analisará a visão de Lênio Luiz Streck em sua crítica às interpretações subjetivas dos magistrados do Poder Judiciário, examinado-se, através da "Teoria da Katchanga"13, a perspectiva detalhada do autor sobre o nexo pressuposto entre jurisprudência e insegurança jurídica.

A criação de uma ciência jurídica livre de sincretismo metodológico tem, segundo Hans Kelsen, a delimitação do objeto de estudo do Direito empreendido pelo cientista do Direito. O positivismo kelseniano serve, nesse sentido, como marco teórico do presente estudo para demonstrar a lógica-normativa e o raciocínio dedutivo. Para o jurista (KELSEN, 1998, p. 387), o sistema jurídico deve funcionar como fator de estabilidade que rege as regras da sociedade e confere segurança aos cidadãos.

Assim, o presente artigo tem como objetivo analisar a relevância desse tema e as repercussões que ele tem ocasionado atualmente no cenário judicial brasileiro. E para examinar as implicações práticas da "Katchanga", inicialmente será elaborado uma explanação sobre esta teoria e sua repercussão no princípio da segurança jurídica.

No que se refere ao núcleo do objeto da análise corrente, a programação do conteúdo desta pesquisa prevê a investigação do planejamento tributário à luz principiológica da segurança jurídica; ou seja, examinar o que acontece dentro do planejamento que, ainda que se forme por atos lícitos, não é capaz de gerar a segurança necessária e esperada de um sistema normativo coerente.

Em razão dos diversos estudos já realizados sobre o planejamento, esse estudo pretende embrenhar-se numa reanálise do direito, tendo como novo foco comparativo a "Teoria da Katchanga", sob o recorte teórico dos motivos e limites que emolduram a arbitrariedade na interpretação legislativa e ao mesmo tempo segurança no sistema normativo.

Desponta, nessa perspectiva, uma necessidade de se reanalisar o planejamento tributário (tema de enorme valia para a seara fiscal) à luz da segurança jurídica para o ordenamento brasileiro (matéria que ganha cada vez mais repercussão tendo em vista os novos problemas e impactos que a ela se relacionam). ${ }^{14}$ De tal modo, como afirma Welber Barral (2003, p. 64), a coerência deve

\footnotetext{
${ }^{13}$ Convém registrar que não se pretende neste estudo realizar uma abordagem detalhada de todas as teorias existentes na doutrina jurídica. O intuito desta pesquisa restringe-se a realizar uma apreciação da denominada "Teoria da Katchanga" e sua metáfora com a dogmática jurídica atual do poder jurisdicional.

14 “A segurança jurídica é realizada por meio da obediência às garantias constitucionais do contribuinte, que passam obrigatoriamente pelas limitações constitucionais ao poder de tributar. Surge, nesse ponto, a supremacia da legalidade em matéria tributária, que tem como consequências imediatas a necessidade de efetivação da tipicidade fechada, que traz a taxatividade para as hipóteses de incidência, e a proibição da tributação por analogia. Nunca se olvide da
} 
ser a primeira das características inerentes a qualquer projeto, considerando o encadeamento lógico entre o tema, os objetivos e a fora de execução.

Assim, a pesquisa ora debatida buscará, inicialmente, relacionar os conceitos hermenêuticos que envolvem esses dois grandes temas para examinar, em seguida, os desdobramentos jurídicos que podem ser obtidos conforme predispõe a legislação e as consequências jurisprudenciais verificadas atualmente sobre esses assuntos na atuação das Cortes Superiores brasileiras.

Segundo o direito civil, o uso ilícito da pessoa jurídica funciona como o principal condicionante para aplicar o instituto da desconsideração da personalidade jurídica, cujos efeitos são ou podem ser anulados com relação aos terceiros de boa-fé, num particular momento e em determinadas circunstâncias. Com isso, o ponto fulminante a esse respeito é específico e detalhado: como saber o momento certo para haver tal desconsideração jurídica?

Diante dessa questão, alguns doutrinadores defendem que é necessário presumir-se a boafé negocial. Mais do que alegar abuso de forma ou falta de propósito negocial, como as autoridades fiscais comumente fundamentam a desconsideração da personalidade jurídica, é necessário que seja evidenciado atos reais de dissimulação. ${ }^{15}$

Assim, o presente estudo possibilitará especificamente: (i) entender como o conceito, a estrutura e a face procedimental da norma jurídica relacionam-se com os fundamentos da obrigação tributária; (ii) ponderar sobre a relação da segurança jurídica no que se refere à liberdade, à cidadania e ao paradigma do Estado Democrático de Direito no desenvolvimento de suas políticas públicas; (iii) examinar os institutos elementares da interpretação jurídica com base na função principiológica e o papel do intérprete não-autêntico; (iv) avaliar se o STF utiliza de fato de seu poder de "Guardião da Constituição" e última instância recursal para proferir decisões marcadas, como denominou Lênio Streck, pela "Katchanga Real"; e (v) identificar o panorama fiscal subjetivo diante do negócio jurídico indireto e da arbitrariedade na aplicação da abertura semântica normativa.

liberdade de atuação dentro da ordem econômica e comercial, sempre atrelada aos limites impostos pela lei." (FOSSATI, 2006, p. 145).

15 "Saber se o fato gerador deve ser considerado ocorrido porque seus efeitos econômicos ocorreram, ou porque a forma jurídica é a prevista na lei, ou porque o perfil objetivo do ato praticado é o mesmo do previsto na lei etc. são questões aliadas a outras, que dizem respeito à interpretação da lei tributária, com repercussão no perfil que se pretenda dar à tipicidade nessa matéria”. (GRECO, 2004, p. 412). 
Dito isso, é válido distinguir que a linha metodológica concebida no plano desta composição segue o sentido jurisprudencial, por se configurar a exposição dialética entre o ordenamento jurídico e o problema localizado, ambos caracterizados como pressupostos coordenados, complementares e irredutíveis do juízo jurídico.

Seguindo essa linha, a técnica de abordagem utilizada para esta pesquisa social aplicada e jurídica será a vertente jurídico-dogmática, cujo Direito busca, com base no raciocínio hipotéticodedutivo, fundamentar toda a lógica e os procedimentos nas próprias normas que suplementam o ordenamento pátrio.

Preliminarmente, o corte material delimitado no universo desta pesquisa se configura dentro do âmbito constitucional especificamente relacionado aos preceitos fundamentais da segurança jurídica, da estrita legalidade e da capacidade contributiva. Num segundo nível de aprofundamento, será verificado se há vicissitude existente nos conceitos indeterminados e na abertura semântica normativa e como isso está relacionado com os princípios constitucionais observados na prática jurídica.

A conceituação e a interpretação jurídica podem ser elementos chaves para a detecção dos pressupostos de conceitos indeterminados (como simulação, fraude e abuso de forma) e a determinação da abertura dessa semântica normativa para o planejamento tributário.

Os fatores evasivos descritos pela norma e pelo panorama fiscal subjetivo levam a uma contaminação do entendimento do ente fiscalizador no enquadramento do conceito de evasão e na interpretação arbitrária da lei. E isso ocorre justamente porque o contribuinte fica à revelia diante dos pluralismos metodológicos das entidades fiscais e da pressuposta ausência de limites objetivos na implementação da norma, pois o Fisco aparenta interpretar de modo subjetivo quais operações jurídicas devem ser ou não desconsideradas.

Com efeito, a metodologia a ser utilizada consistirá na realização de pesquisa na doutrina e legislação nacional, analisando o sistema jurídico do Brasil (constitucional, tributário e processual), notadamente com relação à segurança jurídica e a aplicação do instituto da simulação.

Nessa qualidade, na primeira fase de conhecimento do objeto deste estudo, será adotado um aprofundamento das leituras bibliográficas, análise da legislação e avaliação crítico-investigativa dos dados obtidos.

Posteriormente, na segunda fase marcada pela investigação, interpretação e qualificação do marco teórico, será elaborado: agrupamento dos dados doutrinários, normativos e jurisprudenciais 
coletados; diagnóstico crítico-ireflexivo dos elementos a serem aprofundados; esquadrinhamento do marco teórico para a teoria discursiva de que se trata; confirmação ou refutação das hipóteses levantadas pela pesquisa; e sopesamento das conexões entre os principais pontos envolvidos no escopo deste estudo (hermenêutica e segurança jurídica).

Pois bem, na terceira fase, então denominada como etapa de discussão e revisão do texto, serão produzidas: comparações conceituais importantes sobre a matéria; ponderações sobre a interpretação jurídica; avaliações sobre a arbitrariedade fiscal na aplicação da norma; revisões do conteúdo; checagens das proposições iniciais; e conferências do conteúdo textual preparado para o presente artigo científico.

Sucessivamente, na quarta e derradeira fase, conhecida como conclusão do texto e divulgação dos resultados obtidos, serão examinadas as modalidades dos aspectos principiológicos e os instrumentos metodológicos de análise do tema com a finalidade de destacar se a ausência de limites para a interpretação dos magistrados ocasiona volatilidade das interpretações jurisprudenciais com a consequente insegurança para os destinatários da norma e todos os aplicadores do Direito.

Por fim, nessa última fase, será verificada a: redação e formatação final do artigo em desenvolvimento; revisão do texto; averiguação da coerência e da fluidez entre o tema proposto, a maturação da substância almejada e a conclusão obtida; avaliação da capacidade de problematização, formulação de hipóteses e aplicação da metodologia adequada à pesquisa e ao desenvolvimento lógico; apresentação da solução final de toda a análise produzida; e publicação dos implicações alcançadas.

\section{ALEGORIA INTERPRETATIVA DA KATCHANGA}

Inicialmente, impende notar que o jurista Lênio Luiz Streck (2012), ao explicar como ocorre a "Teoria da Katchanga", narrou uma história em que dois jogadores se desafiaram certa vez a um jogo chamado "Katchanga". O misterioso desafiante propôs uma disputa valendo prêmios ao desafiado, que se dizia conhecedor de todos os jogos e exímio competidor. Na primeira rodada, o desafiante pegou o baralho, distribuiu dez cartas aleatoriamente, comprou mais três cartas, 
descartou duas e colocou suas cartas sobre a mesa, intitulando-se ganhador da rodada por ter feito a "Katchanga".

Sem entender muito bem o ocorrido, o jogador desafiado tentou buscar a lógica de como deveria fazer para ganhar o jogo e supôs que fosse a formação de duas trincas, conforme viu nas cartas da tal "Katchanga" de seu adversário. Assim, após propor uma revanche ao ganhador, valendo o dobro do prêmio anterior, as cartas foram novamente distribuídas e o jogador desafiado procurou rapidamente formar trincas para reverter sua derrota. Depois de ter comprado quatro cartas, o desafiante gritou "Katchanga" outra vez e disse ser o vitorioso ao revelar orgulhoso que não continha nenhuma trinca, mas sim três pares de cartas.

Ao se julgar agora conhecedor do jogo e de suas artimanhas, o desafiado propôs ao misterioso desafiante mais uma rodada valendo o triplo de todos os prêmios apostados. Deste modo, ao iniciar a terceira rodada já com seu ego ferido, o desafiado ficou satisfeito por ter formado uma trinca de cartas em suas mãos logo em sua primeira compra. No entanto, no momento em que o desafiado iria gritar "Katchanga" para vencer o jogo pela primeira vez, o apostador desafiante se antecipou e disse "Katchanga" primeiro, sorrindo novamente e mostrando de forma presunçosa uma trinca e dois pares de cartas.

Desesperado por se ver humilhado no jogo e azarado por não ter ganhado nenhum prêmio nas três rodadas consecutivas, o aventureiro desafiado propôs uma última e derradeira rodada valendo todos os prêmios, notas e moedas que ele ainda possuía. Era uma revanche arriscada, mas que poderia lhe trazer uma inesperada e grande vitória se conseguisse formar, segundo sua opinião, duas trincas, três pares de cartas ou uma mesclagem dos mesmos.

No decorrer da rodada final, o corajoso desafiado conseguiu formar então uma trinca e dois pares de cartas, vindo a gritar rápida e exageradamente alto "Katchanga", para que todos pudessem ouvir sua triunfante vitória. Porém, o desafiante esboçou vagarosamente um largo sorriso e balançou sua cabeça em sinal de negação, bradando "Katchanga Real”! Para tanto, mostrou uma sequência de cinco cartas de naipes iguais e consecutivas, pegando, enfim, todo o prêmio que estava sendo disputado na mesa.

Ao apreciar essa "Teoria da Katchanga", observa-se que o desafiado se achou conhecedor das regras e se viu frustrado com o resultado e a falta de lógica das regras do jogo. Da mesma forma, como propõe Lênio Streck, as partes litigantes do processo contencioso no Brasil 
cotidianamente também se veem frustradas com as decisões judiciais não pautadas pela lógica da legislação.

Assim sendo, nota-se que essa pequena história da "Teoria da Katchanga" serve, na óptica do referencial trabalhado, para metaforizar a dogmática jurídica do poder jurisdicional e seu vínculo com a segurança jurídica, simbolizando, de tal modo, como as decisões forenses atualmente no país são, em geral, superficiais e incongruentes, assim como ocorreu no jogo.

As jurisprudências estão cada vez mais pautadas na "Katchanga", com pouca sustentação normativa e imersas em posições subjetivas. Como assertivamente apontado pelo jurista Lênio Streck, “do que adianta discutir princípios, separação de Poderes, interpretação jurídica, se, ao fim e ao cabo, o Direito depende exclusivamente das preferências pessoais do juiz?" (STRECK, 2015, p. 43).

Desta feita, cria-se uma falha na coerência jurisprudencial e vasta insegurança para os cidadãos brasileiros. A bem da verdade, como será explorado no capítulo seguinte (mais detalhado e aprofundado), ao se analisar este tema é importante saber qual a base do princípio da segurança jurídica e a sua relação com a interpretação sistêmica, além de avaliar sua correlação, em certa medida, com a confiabilidade para os destinatários do ordenamento jurídico.

\section{SEGURANÇA JURÍDICA NA TEORIA NORMATIVA KELSENIANA}

O presente estudo surge como uma reflexão acerca de um dos pontos substanciais do direito: a segurança jurídica. O cidadão deveria cumprir com todas as suas obrigações e possuir, em contrapartida, segurança na construção de suas relações sociais.

O Direito não consiste numa coletânea aleatória de normas jurídicas desprovidas de qualquer conexão de sentido, mas sim, de um conjunto organizado de normas jurídicas, e, de sua natureza organizada exsurge a convicção de sua ordem, da qual advém a ideia de ordenamento jurídico.

Niklas Luhmann (1986, p. 172) designa "autopoiesis“ como um mecanismo reflexivo do sistema que lhe permite o desdobramento auto-reflexivo, de forma a poder satisfazer as necessidades de plasticidade e estabilidade das suas estruturas num contexto altamente complexo. 
Segundo Luhmann, os meios são os instrumentos eficazes na transformação da improbabilidade da comunicação em probabilidade. Eles "fornecem regras institucionalizadas para determinar quando é que as tentativas de comunicação serão provavelmente bem sucedidas" (LUHMANN, 2006, p. 115).

Com efeito, a comunicação considerada no quadro da Teoria dos Sistemas de Luhmann revela que a CF/88 é o elemento que, em última instância, ordena a totalidade do processo, em torno do qual as áreas específicas do Direito gravitam e estabelecem configurações variáveis. Todas essas áreas do Direito, com ressalva à particularidade de cada uma, devem se relacionar para manterem, deste modo, a coerência e harmonia necessárias ao sistema.

Conforme afirma Luhmann, essa característica sistêmica de comunicabilidade demonstra que os sistemas são operacionalmente fechados, mas devem ser arejados e permeáveis a certas influências ambientais, na infindável tentativa de suprimir sua incompletude e provisoriedade. Em outras palavras, o sistema do Direito deve ser pautado em uma ordem de valores, consubstanciáveis em princípios gerais, que podem transcender e ultrapassar o limitado aspecto do direito tributário positivado. ${ }^{16}$

De acordo com Humberto Ávila (2012b, p. 295), o princípio da segurança jurídica é construído pela interpretação dedutiva do princípio maior do Estado de Direito e pela interpretação indutiva de outras regras constitucionais. Em todas essas normas, a Constituição Federal dá uma nota de previsibilidade e de proteção de expectativas legitimamente constituídas. Sobre este ponto, Heleno Tavares Torres igualmente sustentou que:

A segurança jurídica postula efetividade. Não é um princípio vago. É denso em valores, e seus fundamentos não se podem reduzir ou anular. Por isso, outro aspecto de fundamental relevância a se antecipar é que o princípio de segurança jurídica não está sujeito a ponderações, dado o seu caráter de "garantia" constitucional de proteção do ordenamento jurídico e do próprio Estado Democrático de Direito. (TORRES, 2012, p. 197).

Em linhas gerais, segurança jurídica é o princípio norteador de todos os demais do sistema normativo, pois, em linhas gerais, esse princípio estabelece o "dever de buscar um ideal de estabilidade, confiabilidade, previsibilidade e mensuridade na atuação do Poder Público” (ÁVILA,

\footnotetext{
16 "Portanto, os princípios gerais são manifestações de valores fundantes gerais, que se concretizam em direitos humanos, em acepção ampla, ou seja, em direitos individuais, direitos da liberdade ou direitos fundamentais, inclusive sociais e de liberdades públicas, tão extensos que, neles certamente se incluem as garantias institucionais e processuais de liberdade e ainda a tutela dos direitos e a autotutela da legalidade pela administração.” (DERZI, 2003, p. 92).
} 
2012b, p. 297). E no tratamento sobre o princípio da segurança jurídica, Heleno Torres sustenta que a segurança jurídica é um princípio-garantia constitucional que tem por finalidade:

Proteger direitos decorrentes das expectativas de confiança legítima na criação ou aplicação das normas jurídicas, mediante certeza jurídica, estabilidade do ordenamento ou efetividade de direitos e liberdades fundamentais (TORRES, 2012, p. 26).

Traçadas, pois, as balizas fundamentais da segurança jurídica, a teoria kelseniana apresentase como relevante contribuição para o estudo da ciência do direito e sua compreensão, porque discorre sobre um dos grandes problemas jurídicos da sociedade contemporânea: a interpretação normativa como elemento progenitor da insegurança dos cidadãos.

Ao Poder Judiciário não é facultado, portanto, inovar subjetivamente em seus julgamentos. Sobre esse ponto, Alberto Xavier (2001, p. 139) com muita propriedade manifestou que a "criatividade do aplicador do Direito é incompatível com as exigências estritas da separação dos poderes (reserva absoluta de lei) e da segurança jurídica (previsibilidade, proteção de confiança)".

Na moldura kelseniana, o raciocínio interpretativo para aplicar corretamente uma norma deve encontrar respaldo no próprio ordenamento em que está inserido. Não há necessidade de sair do âmbito do direito para que se permita solucionar uma determinada nova situação social.

A Constituição Federal de 1988 consagrou inúmeros princípios, implícitos e explícitos, com vistas a assegurar a cada pessoa a observância e o cumprimento de seus direitos e de suas garantias por parte do Estado. Esta incursão é requisito indeclinável para a identificação dos preceitos válidos e vigentes, em contraposição àqueles que não mais compactuam com a realidade posta.

Nas palavras de Paulo de Barros Carvalho (1996, p. 53), "a legalidade não é um valor em si, é um limite objetivo. Obviamente, é um limite objetivo que persegue um valor, e esse valor, nós já sabemos, é a segurança jurídica”. Edimur Ferreira de Faria (2015, p. 569) defende a ideia de que a responsabilidade civil do Estado passou por processo mutativo. Inicialmente, o Estado era concebido como irresponsável, tendo em vista que ele estava acima do Direito. Da irresponsabilidade evoluiu-se para a responsabilidade com culpa (subjetiva), chegando, finalmente, à possuir responsabilidade objetiva (sem culpa).

O princípio da estrita legalidade garante aos cidadãos a concretização dos ideais de justiça e segurança jurídica. "No ordenamento jurídico esta subsunção será considerada como a aplicação do princípio da legalidade e da segurança jurídica, que integram o suporte normativo para todos os efeitos jurídicos” (BERNARDES, 2006, p. 78). Como aponta Alberto Xavier (1978, p. 37), o 
princípio da legalidade visa "proteger a esfera de direitos subjetivos dos particulares do arbítrio e do subjetivismo do órgão de aplicação do juiz". Afinal, como ensina Ronaldo Brêtas de Carvalho Dias (2012, p. 92), “o juiz não cria (ou inventa) direito algum no processo que possa ser considerado democrático".

Neste sentido, o raciocínio jurídico por meio da relação lógica entre preceitos e sua incidência sobre um dado fático tem como base a lógica evidenciada na seguinte equação: quando se analisa a característica sancionadora do sistema "Se A, deve ser B. Se não B, deve ser C". Como cediço, "A" são as condições de aplicabilidade da norma que determina o resultado "B", sendo ambos polissêmicos, a depender da tessitura de incidência de uma dada regra. Por outro lado, se a ação humana não se dá conforme 'B”, então o ordenamento prevê uma determinada consequência jurídica, designada de sanção e representada por " $C$ ".

O positivismo de Hans Kelsen serve, ${ }^{17}$ nesse sentido, como marco teórico que evidencia assertivamente o que dispõe e o que se deve esperar da norma. Nas palavras de Sacha Calmon Navarro Coêlho (2003, p. 45), "se a norma jurídica é o objeto do conhecimento jurídico na gnosiologia Kelseniana, o ‘juízo hipotético’ que o cientista do Direito constrói ao descrevê-la só pode ser uma 'proposição' a respeito da norma, nunca a 'norma-em-si'”. E exatamente por ser uma proposição, ou seja, a abstração da norma em um preceito linguístico descritivo, a análise do cientista do Direito deve ser revelada sem a influência de valores do tipo "norma má; norma boa" ou "norma justa; norma injusta".

Ocorre que, segundo o Mestre de Viena, a interpretação normativa não pode ser aleatória, individualizada e proveniente de interesses externos ao direito. Para Hans Kelsen (1998, p. 387), a interpretação jurídica deve ser uma operação mental que acompanha o processo de aplicação do Direito através de uma leitura sistêmica, ou seja, percorrendo o ordenamento.

Hans Kelsen também defendia que a pureza metodológica significava ter um princípio metodológico fundamental no qual o Direito, assim entendido como sistema normativo harmônico, coeso e sancionador, utilizava-se de um único método jurídico. Isso implica a eliminação da ciência

\footnotetext{
${ }^{17}$ Refere-se, de início, à obra do professor Hans Kelsen por ser adotada como o marco teórico do estudo da estrutura da norma jurídica tributária (normas de conduta e sancionantes), na sua concepção hipotética. Não constituindo objeto do presente trabalho a sistematização das diversas teorias que conceituam a norma jurídica, nem se pretende, obviamente, desprezar a importância de toda a evolução do estudo do Direito desde os jusnaturalistas, passando pela Escola Histórica do Direito, Escola do Realismo Jurídico, da Teoria Imperativista dos juízos categóricos e outras. Ressalva-se, contudo, que não há a adesão absoluta aos posicionamentos explicitados na obra Teoria Pura do Direito, mas apenas e tão-somente ao que se refere à estrutura normativa, não se adentrando nos demais aspectos do positivismo jurídico e seus diferentes formatos existentes.
} 
jurídico-política, do viés sócio-jurídico, da análise econômico-jurídica ou de qualquer método que não seja o próprio ordenamento jurídico para fundamentar a ciência jurídica.

Ao longo de sua vida como investigador do Direito, Kelsen buscou fundamentar todas as suas teorias na reflexão estritamente científica. Quando há introdução de elementos estranhos ao Direito, o sistema perde sua harmonia e quebra sua coerência normativa. ${ }^{18}$

Impende notar que a pureza da ciência kelseniana depende estritamente da neutralidade axiológica, pois esse distanciamento com as ideologias e aspirações axiológicas demonstrou ser condição necessária para a concretização da argumentação jurídica.

Uma decisão judicial deficiente abre brechas para que a própria dogmática jurídica seja questionada, fazendo surgir, nessa dicção, como será visto no próximo tópico, universos jurídicos sem limites para as interpretações dos magistrados e cidadãos desconfiados. ${ }^{19}$

Assim, no regime do sistema da civil law adotado no direito brasileiro, a jurisprudência possui o papel de uniformização da inteligência dos enunciados das normas que formam o ordenamento jurídico. Essa função jurisprudencial é, aliás, uma das formas do direito processual prestigiar, acima de tudo, a segurança jurídica.

A função constitucional da jusprisprudência é harmonizar e uniformizar as decisões judiciais de modo a conferir coerência e estabilidade ao sistema. O novo Código de Processo Civil procura garantir uma estabilidade aos precedentes e efetividade aos princípios constitucionais.

O ordenamento jurídico não pode ser visto desvencilhado dos fatos que ocorrem ao seu redor e não pode pretender extrair, de um só caso concreto, uma solução que a todos sirva. Ato contínuo, apesar de ser possível extrair essa diretriz no antigo CPC, o novo CPC tomou algumas providências para trazer fazer cessar de modo mais claro as jurisprudências divergentes que versem

\footnotetext{
18 "Esta pureza metodológica torna-se absolutamente indispensável para garantir a cientificidade da jurisprudência e sua autonomia em face da sociologia e da política do Direito. Deixar que outros critérios, além dos pensamentos formais, informem o processo mental do jurista é cair no "sincretismo metodológico" da jurisprudência tradicional que, por isso mesmo, não satisfaz aos requisitos da cientificidade.” (KELSEN, 1963, nota preambular). E nesse mesmo fundamento, "boa parte da jurisprudência tradicional é caracterizada por uma tendência para confundir a teoria do Direito positivo com ideologias políticas disfarçadas. [...] É precisamente por seu caráter antiideológico que a teoria pura do Direito prova ser uma verdadeira ciência do Direito. [...] O postulado de uma separação completa entre jurisprudência e política não pode ser sinceramente questionado caso deva existir algo como uma ciência do Direito" (KELSEN, 1992, p. 3-4).

${ }^{19}$ A Teoria dos Precedentes foi reincorporada através do novo Código de Processo Civil exatamente para tentar evitar este cenário, buscando coerência na jurisprudência. Este instituto, oriundo da common law, tem por escopo a construção de entendimentos amparados no âmbito dos tribunais e que passam a se revestir de um caráter obrigatório e até mesmo vinculante perante as demais instâncias com relação aos fundamentos adotados para proferir a decisão.
} 
sobre o mesmo tema. A observância dos precedentes, quanto mais é analisada, mais e mais vantajosa e consentânea ela se demonstra ser com um modelo constitucional de Processo Civil.

Inicialmente, as jurisprudências que detinham reiteração e uniformidade ganharam um caráter sumular sem força vinculativa, mas com evidente autoridade para revelar os posicionamentos das Cortes superiores. Hoje em dia, até mesmo as súmulas não-vinculantes são fatores decisivos para agilizar os julgamentos sumários, como dispõem de forma especial os artigos 332, 927 e 985 do novo Código de Processo Civil (CPC). ${ }^{20}$

Com efeito, observa-se que o novo CPC teve uma grande preocupação em focar nas jurisprudências dominantes, como destacou Humberto Theodoro Júnior:

Significa dizer que de nada adianta o CPC ter dedicado tratamento especial à jurisprudência se não houver uniformidade e coerência entre elas. Essa harmonização da jurisprudência contribuirá de modo essencial para que os casos fáticos (sobre os quais o magistrado tenha que decidir) respeitem os princípios da legalidade, da segurança jurídica, da proteção, da confiança e da isonomia.

De igual modo, o parágrafo $4^{\circ}$ do artigo 927 do novo CPC reproduziu expressamente este entendimento ao ressaltar que a modificação de jurisprudência consolidada "observará a necessidade de fundamentação adequada e específica, considerando os princípios da segurança jurídica, da proteção da confiança e da isonomia" (BRASIL, 2015).

Em outras palavras, verifica-se que o novo CPC atribuiu formalmente a valorização da jurisprudência e o sistema de súmulas. Os magistrados dos tribunais superiores devem ter neutralidade axiológica, pois, como expressa Baracho Júnior (2000), o procedimento da atuação judicial, como forma de participação política, enfraquece a imparcialidade, a positivação do direito e a sua racionalidade.

O novo CPC trouxe uma responsabilidade ainda maior para os desembargadores e os ministros dos Tribunais Superiores, já que a jurisprudência que se enquadrar nos artigos 332, 927 ou 985 do CPC tem força legal para ser seguida pelos tribunais inferiores. Todavia, caso essa jurisprudência esteja embasada em argumentos sociais, políticos ou econômicos da época em que foi formada, ela se tornará viciada e eivada de elementos estranhos ao sistema normativo,

\footnotetext{
20 "A garantia fundamental da segurança jurídica, em termos de uniformização e previsibilidade daquilo que vem a ser o efetivo ordenamento jurídico vigente no país. Entretanto, para que essa função seja efetivamente desempenhada, a primeira condição exigível é que os tribunais velem pela coerência interna de seus pronunciamentos." (THEODORO JÚNIOR, 2016, p. 170).
} 
contaminando todos os outros casos judiciais que estiverem legalmente obrigados a seguirem a mesma decisão tomada. De forma analógica, será o mesmo que contradizer o parágrafo $4^{\circ}$ do artigo 927 do CPC e propagar a insegurança no sistema jurídico.

A Teoria Pura do Direito de Kelsen, como considerou Jair Gonçalves (2001, p. 45-46), não é uma teoria pertencente a um Direito positivo e ultrapassado porque pretende descrever o fenômeno jurídico mediante uma série de conceitos formais presentes em qualquer época ou lugar em que forem aplicados. Kelsen não negou a existência de uma certa relação entre as disciplinas afins à ciência jurídica (sociologia, política, economia, etc.), mas prescindir de elementos sociológicos, políticos e éticos é uma exigência da pureza metodológica que deve vigorar para a formação de uma jurisprudência jurídica realmente bem estruturada.

Noutra dicção, “o trabalho do jurista científico está delimitado pelo marco da legalidade, ainda que a crítica da legalidade seja qualificada de política e de juízo subjetivo de valor" (GONÇALVES, 2001, p. 49). Aliás, “a Corte está encarregada de fazer prevalecer a vontade profunda do povo (na Constituinte) contra a vontade episódica da maioria de seus representantes, que fazem as leis" (DERZI, 2004, p. 9).

As normas jurídicas são criadas visando a produção de determinados efeitos e não podem, via de regra, constituir um fim em si próprias. O jurista, diante da realidade fática, não deve julgar as normas do ordenamento sem compreender o caráter semântico do mesmo. Nesse âmbito, os fatos jurídicos apresentam-se como fenômenos de causa e efeito, cuja fórmula relacional necessita de sentido e coerência.

Como se verá nos tópicos a seguir, a influência de fatores externos (juridicamente nãojustificáveis por meio das regras jurídicas), não pode ser absorvida sob o pressuposto de se aplicar princípios jurídicos. A interpretação econômica, política ou sociocultural da norma não pode servir como lastro para integrar argumentos externos ao âmbito jurídico.

A bem da verdade, o novo CPC estabelece de forma mais clara a importância da coerência do sistema jurídico, já que a função do Poder Juridiciário no sistema da civil law é garantir esta coesão. As decisões jurídicas devem procurar a ratio decidendi sobre a qual o enunciado de súmula se assenta para realizar uma interpretação adequada e garantir a coerência da jurisprudência. Caso contrário, haverá diminuição da confiança dos cidadãos nas decisões da Corte Suprema e consequentemente dos demais órgãos jurisdicionados. 


\section{BASE NORMATIVA E PRINCÍPIO METODOLÓGICO}

É imprescindível acentuar que não se pode realizar uma análise completa do direito sem avaliar os dois lados do problema. A base empírica de qualquer estudo jurídico deve considerar não somente a tese adepta ao raciocínio proposto, mas também a sua antítese e os principais argumentos que a contrapõe, como se pretende demonstrar neste momento.

Os defensores da interpretação subjetiva defendem que o direito deve se adaptar à realidade que o circunscreve. "No contexto positivista, a técnica produz a crença na segurança no Direito a partir de tipos fechados e conceitos determinados." (CRUZ, 2012, p. 22). Nesta lógica, os críticos ao positivismo e ao sistema jurídico "fechado" defendem que existem conceitos jurídicos indeterminados que somente podem ser realmente concretizados com o protagonismo da jurisprudência e as sucessivas aplicações das decisões judiciais em cada caso. ${ }^{21}$

Desse modo, os críticos ao positivismo kelseniano sustentam que objetivo final não é somente dar mais liberdade para os magistrados, mas possibilitar ao Poder Judiciário uma abertura mais ampla de atuação, sem aqui adentrar se poderiam ser considerados ativistas ou não. Do contrário, estar-se-ia, sob esse ponto de vista, condenando o sistema jurídico ao gesso fixo e inflexível que as normas criam. ${ }^{22}$

Na visão destes críticos ao cientificismo jurídico, o direito está inserido na sociedade humana que, independentemente da época ou lugar em que exista, não consegue dissociar-se de sua história, cultura, política, economia ou grupos sociais. Na relação homem-sociedade, o

21 “Codificar a sanção da fraude à lei ou incluí-la num dispositivo legal expresso não é, portanto, necessário para combater as fraudes, como demonstra a jurisprudência brasileira. [...] Ainda que o instituto esteja previsto num artigo de lei (como ocorre agora com o artigo 166, VI, do Código Civil de 2002), o protagonismo continuará sendo da jurisprudência, pois a fraude à lei, como o abuso do direito e a boa-fé, é um conceito jurídico indeterminado, uma cláusula geral que somente vai se cristalizando com sucessivas aplicações jurisprudenciais." (GODOI, 2007). Ademais, o "formalismo jurídico desmedido fundado num exacerbado conceito de certeza do direito, no discutível postulado da intangibilidade dos esquemas formais e na indefectível superposição de tais sistemas à realidade econômica subjacente" (HUCK, 1997, p. 243).

22 "Permitam-me apresentar-lhes o juiz Ivan Ilitch. À primeira vista, apenas um personagem de Tolstoi, um habitante do mundo da ficção. Mas não nos enganemos, Ivan Ilitch é mais do que real. [...] Ivan Ilitch dá um rosto à imprudência moderna. Ele é o juiz bem sucedido, que crê desempenhar perfeitamente o seu papel, ou seja, que "aplica" o Direito. [...] Ele "aplica" o direito, mas não sabe (ou finge não saber) que o Direito não pode ser "aplicado" de uma forma mecânica. Sua prudência (no sentido moderno), que se manifesta em sua dócil submissão a um legalismo convenientemente apropriado ao carreirismo, é máxima imprudência (no sentido clássico). E por essa imprudência, Ivan Ilitch paga um preço alto. O preço da falta de sentido, cobrado na moeda de um sofrimento total." (DE OLIVEIRA, 2005). 
positivismo kelseniano não consegue acompanhar as novas relações sociais que surgem e, por isso, não cumpre com a finalidade social do Poder Jurídico dentro da comunidade em que está inserido. ${ }^{23}$

De fato, não se pode pender para o exagero de nenhum extremo de uma lógica imparcial, racional e coesa. Porém, hoje se vivencia no Brasil a incerteza jurisprudencial, em que há nítidas evidências de que a maneira como ocorre as decisões judiciais postas pela Suprema Corte (e consequentemente pelas demais instâncias jurisdicionais) não possuem orientações padronizadas e bem desenvolvidas, necessitando, por isso, serem aprimoradas.

O problema, porém, não é a mudança em si, mas os seus efeitos. Se ela surpreender o indivíduo que exerceu intensamente os seus direitos de Liberdade e de propriedade confiando e podendo confiar na sua permanência, a mudança de orientação pode ter efeitos negativos expressivos. (ÁVILA, 2012a, p. 471).

Neste aspecto, o problema surge justamente quando todos esses pontos expostos não ocorrem e o juiz produz deliberações lastreadas em sua opinião própria, com fundamentos insatisfatórios, interesses diversos (estranhos ao sistema jurídico) e pontos contraditórios.

É válido lembrar que não se pode falar em segurança jurídica quando não há respeito aos conceitos e às regras positivadas. $\mathrm{O}$ cidadão não pode esperar que um ministro do STF tenha liberalidade de fluir livremente no campo da subjetividade para decidir se uma determinada norma questionada judicialmente deve seguir o que predispõe a lei ou se, em virtude da economia, de interesses políticos, repercussões sociais ou estratégias governamentais o acórdão da Suprema Corte será decidido de uma outra e inesperada forma. ${ }^{24}$

Não basta que haja um julgamento legalmente válido apenas porque foi proferido pelo “guardião da Constituição Federal". É imprescindível que haja sempre um equilíbrio na equação: legitimidade e coerência no veredito, além de uma justificação normativa detalhada sobre cada ponto deliberado.

\footnotetext{
23 “A tese central do conceito de direito de Alexy é que a ponderação adequada entre os princípios da justiça de primeira ordem e da segurança jurídica é realizada pelo não-positivismo inclusivo, que reconhece a importância da segurança jurídica, mas admite exceções a ela, quando a injustiça é extrema. [...] O argumento da injustiça já constitui o resultado de uma ponderação: a segurança jurídica tem precedência sobre a correção moral ou justiça (de primeira ordem), exceto em casos de injustiça extrema. Em virtude disso, outra estratégia deve ser adotada." (TRIVISONNO, 2015, p. 111$112)$.

24 "Quando alguém consegue entender "as regras", ela mesma, a própria dogmática, tem sempre um modo de superar os paradoxos e decidir a "coisa" ao seu modo. [...] Ora, na verdade, o que deve ser dito é que a ponderação à brasileira não é uma representação de uma "teoria da Katchanga" (sic), mas, sim, ela própria é a Katchanga no modo como "a joga" a dogmática jurídica. Ela representa uma forma de decidir, e afirmar, assim, o non liquet. O "mito Katchangal" está presente na própria teoria de Alexy e no elemento decisionista inerente ao seu procedimento ou fórmula da ponderação." (STRECK, 2012).
} 
De nada adianta a reforma processual do CPC, na ótica do positivismo normativo, se ainda existir insegurança jurídica e desconfiança dos jurisdicionados com relação às decisões proferidas pelos Tribunais brasileiros. A mudança de orientação deve ser exaustivamente justificada e sempre deve respeitar as posições anteriormente consolidadas, de acordo com a moldura legal. ${ }^{25}$

De igual sorte, o autor Lucas Buril Macêdo (2015, p. 1) reforçou esse posicionamento ao afirmar que a criatividade jurisdicional existe e para que ela seja devidamente tratada (evitando-se a perniciosa esquizofrenia jurisprudencial que se vê atualmente), é essencial que, primeiro, ela seja reconhecida.

Caso contrário, haverá dissonância interpretativa entre tribunais superiores e os tribunais de base (notório conflito entre função institucional e segurança jurídica). E mais, os julgadores poderão entrar em contradição com a jurisprudência de outros tribunais ou até do mesmo órgão ao qual pertencem, instalando o verdadeiro "manicômio jurisprudencial” no Estado Democrático de Direito, como asseverou Ronaldo Brêtas (2012, p. 144) ao se referir ao atual cenário contraditório e divergente dos tribunais brasileiros.

Os acórdãos gerados pelos Tribunais de Justiça dos Estados e do Distrito Federal desconhecem sumariamente a jurisprudência constitucional do Supremo Tribunal Federal, atentando contra a ordem constitucional, a estabilidade do direito e a segurança jurídica. (BRÊTAS, 2012, p. 139).

Deve haver de fato mudança para que as normas do Sistema não fiquem defasadas em relação à realidade. Não obstante, não pode haver alteração jurisprudencial que não possua sentido lógico normativo, ampla fundamentação e respeito ao entendimento vigente no passado. O que se busca é que haja, de certo modo, evidências de permanência na mutação. O dinamismo do Direito deve ser diretamente vinculado e dependente das normas jurídicas que o integram; ou, do contrário, a própria dogmática jurídica abrirá margens para aplicação da "Katchanga” judicial.

Uma decisão judicial deficiente abre brechas para que a própria dogmática jurídica seja questionada, fazendo surgir, nessa dicção, como será visto no próximo tópico, universos jurídicos sem limites para as interpretações dos magistrados, cidadãos desconfiados e jurisprudências da "Katchanga". Se o sistema buscar se fundamentar com elementos fora do próprio sistema, a lógica

\footnotetext{
25 "Esse quadro de divergência decisórias, especialmente porque delineado no âmbito desta Suprema Corte, compromete um valor essencial à estabilidade das relações entre o Poder Público, de um lado, e os contribuintes, de outro, gerando situação incompatível com a exigência de segurança jurídica, que se agrava ainda mais por se instaurar em matéria tributária, em cujo âmbito se põem em evidência as relações sempre tão estruturalmente desiguais entre o Estado e as pessoas em geral.” (Ação Cautelar/QO 1.886, 2ª Turma, Rel. Min. Celso de Mello, DJe 07.11.2008).
} 
normativa não será congruente e se tornará insustentável porque dar-se-á uma margem interpretativa da Lei Maior sob a ótica econômica, política, pragmática, teleológica, gramatical, histórica ou social.

É necessário haver limites para que cada decisão do STF não seja proferida como uma "Katchanga" impositiva, que deverá simplesmente ser aceita pelo cidadão brasileiro. "Alguns parâmetros vêm sendo selecionados pela doutrina especializada, na tentativa de estabelecer limites ao poder discricionário" (FARIA, 2015, p. 196).

Na visão de Lênio Streck, atualmente "há uma plêiade de fatores a influenciar a decisão que ficam de fora dessas análises estritas do fenômeno jurídico e do modo de se retratar, tradicionalmente, o papel da dogmática jurídica" (STRECK, 2012, p. 1$){ }^{26}$

O direito existe para ser aplicado. Antes, porém, é preciso interpretá-lo. Só aplica bem o direito quem o interpreta adequadamente para que haja uma resposta jurídica coerente e satisfatória até para as situações mais complexas que ainda se encontram em desamparo de lei expressa. Como afirmou Flávio Bernardes (2006, p. 161-162), a unidade da ciência jurídica e a eficácia do ordenamento somente ocorrem pela integração e coordenação de suas normas.

As decisões jurisprudenciais podem sofrer alterações no que se refere aos seus precedentes, mas a mudança de orientação jurisprudencial deve ser bem justificada, baseada no sistema jurídico, ou do contrário ocorrerá a "Katchanga" judicial. Há um limite gnosiológico para se estabelecer a possibilidade de uma interpretação literal e "seca" da lei, mas a interpretação deve ser menos subjetiva e mais adequada à conformação da segurança jurídica.

O principal problema atualmente é a excessiva utilização de interpretações "contra legem" de mutações constitucionais e de viradas jurisprudenciais sem a devida sinalização de tal mudança. Combate-se, então, a inovação do ordenamento jurídico por via judicial (o que deve ser feito, em um Estado Democrático de Direito, pelo Poder Legislativo - levando-se em consideração, em alguma medida, a possibilidade de coparticipação dos demais poderes).

\section{JURISPRUDENCIA CONSTITUCIONAL DA KATCHANGA}

\footnotetext{
${ }^{26}$ No mesmo sentido, Láudio Camargo Fabretti dispôs que "na interpretação da lei, tanto o juiz como a autoridade administrativa devem integrar, isto é, inserir a lei no sistema de direito vigente. A interpretação deve ser sistêmica, ou seja, o intérprete deve analisar toda a legislação pertinente e intimamente relacionada com a norma jurídica que pretende investigar." (FABRETTI, 2005, p. 144).
} 
Inicialmente, para demonstrar a desconfiança na jurisprudência constitucional tributária, pode-se citar o caso do Recurso Extraordinário 574.706/PR ${ }^{27}$ no qual o Supremo Tribunal Federal decidiu que o governo federal não pode incluir o Imposto sobre Circulação de Mercadorias e Serviços (ICMS) na base de cálculo das contribuições para o Programa de Integração Social (PIS) e para a Contribuição para o Financiamento da Seguridade Social (Cofins). O tema já estava em discussão há quase 20 anos e contribuiu com incontáveis processos na justiça.

Registre-se, por oportuno, que em 2014 os ministros chegaram a julgar um caso individual desvinculando o ICMS da forma de cálculo do PIS e da COFINS, sendo que, à época, como o caso não tinha repercussão geral, a decisão de exclusão do ICMS da base de cálculo do PIS e da COFINS vigorou apenas para o caso específico. Com isso, outros milhares de processos que solicitavam a mesma mudança de cálculo continuaram tramitando na Justiça e aguardando a mesma decisão desvinculadora do ICMS que somente ocorreu vários anos mais tarde.

O Estado de Direito significa, dentre outros aspectos, previsibilidade das ações do Estado; boa-fé no trato dos cidadãos contribuintes de forma segura [previsível, certa, limitada] e justa [porque certa, previsível, limitada]. (COÊLHO, 2005, p. 109).

Nessa jurisprudência em especial, nota-se que foram necessários quase 20 anos para que o direito de se calcular o PIS e a COFINS ocorresse sem a oneração do ICMS. A longa demora em ver restaurada a legalidade do contribuinte fere, por si só, a confiança do cidadão perante a verdadeira eficácia do sistema jurídico.

Com efeito, se o PIS e a COFINS não deveriam ser onerados pelo ICMS, o fato de o contribuinte ter de esperar aproximadamente 20 anos para ver esse direito corrigido gera insatisfação e insegurança para a sociedade. Insegurança essa que está diretamente atrelada à perda de confiança na funcionalidade do ordenamento jurídico e nos reais motivos que embasaram a boa-fé do STF em ter prorrogado tanto tal correção de entendimento tributário.

27 “RECURSO EXTRAORDINÁRIO COM REPERCUSSÃO GERAL. EXCLUSÃO DO ICMS NA BASE DE CÁLCULO DO PIS E COFINS. DEFINIÇÃO DE FATURAMENTO. APURAÇÃO ESCRITURAL DO ICMS E REGIME DE NÃO CUMULATIVIDADE. RECURSO PROVIDO. [...] O ICMS não compõe a base de cálculo para incidência do PIS e da COFINS. [...] 4. Recurso provido para excluir o ICMS da base de cálculo da contribuição ao PIS e da COFINS.” (Recurso Extraordinário 574.706/PR, Tribunal Pleno, Rel. Min. Cármen Lúcia, DJe 29.09.2017). 
Por outro lado, o STF, através da Ação Direta de Inconstitucionalidade (ADI) n. 3.106/ $\mathrm{MG}^{28}$ afastou a compulsoriedade da denominada "contribuição" para a saúde disposta no parágrafo $4^{\circ}$ do artigo 85 da Lei Complementar n. 64/2002. O IPSEMG não pode obrigar os servidores públicos do Estado de Minas Gerais a contribuir com o custeio de serviço de saúde. A segurança jurídica foi, neste aspecto, restaurada ao extrair o termo "compulsoriamente" e tratar a cobrança desta contraprestação apenas como uma facultatividade, pois a compulsoriedade vigorava como um tributo não instituído pela Constituição Federal de 1988.

Todavia, o STF modulou os efeitos dessa decisão (sob o efeito ex nunc) em Embargos de Declaração ao reconhecer a impossibilidade de repetição de indébito das contribuições recolhidas junto aos servidores públicos do Estado de Minas Gerais até a referida data de julgamento do mérito da decisão (14 de abril de 2010). A manifesta inconstitucionalidade foi declarada como válida apenas após a publicação dessa decisão. Antes de 14.04.2010, a expressão "compulsoriamente", apesar de inconstitucional, não pode, com a modulação de efeitos do STF, ser questionada pelos servidores públicos. Trata-se, com isso, evidente afronta à isonomia, segurança jurídica e confiança dos servidores perante a $\mathrm{CF} / 1988$.

Nesse caso, a jurisprudência utilizou de fundamentos externos ao Direito (considerando a alegação de grave prejuízo e instabilidade às finanças do IPSEMG) para justificar a modulação de efeitos. Apesar da evidente contradição à Constituição Federal e ao Código Tributário Nacional, a cobrança pelos serviços de saúde tornou-se legítima pelo IPSEMG até 14.04.2010.

Ademais, vale apontar mais um exemplo de uma jurisprudência constitucional tributária relacionada à quebra da confiança e da segurança jurídica ocasionada pela Emenda Constitucional (EC) $n^{\circ} 41 / 2003$. Os cálculos dos valores dos proventos das aposentadorias e das pensões dos servidores públicos foram modificados. Porém, segundo o parágrafo $2^{\circ}$ do artigo $3^{\circ}$ da EC 41/2003, os valores já exercidos até a data de publicação dessa Emenda puderam manter o cálculo de acordo com a legislação em vigor à época em que foram atendidos os requisitos nela estabelecidos para a concessão desses benefícios.

\footnotetext{
28 “EMBARGOS DE DECLARAÇÃO NA AÇÃO DIRETA DE INCONSTITUCIONALIDADE. ARTIGOS 79 e 85 DA LEI COMPLEMENTAR N. 64, DE 25 DE MARÇO DE 2002, DO ESTADO DE MINAS GERAIS. [...] AÇÃO DIRETA JULGADA PARCIALMENTE PROCEDENTE, DECLARANDO-SE INCONSTITUCIONAIS AS EXPRESSÕES "COMPULSORIAMENTE" e "DEFINIDOS NO ART. 79". INEXISTÊNCIA DE "PERDA DE OBJETO” PELA REVOGAÇÃO DA NORMA OBJETO DE CONTROLE. PRETENSÃO DE MODULAÇÃO DE EFEITOS. PROCEDÊNCIA. EMBARGOS DE DECLARAÇÃO ACOLHIDOS PARCIALMENTE.” (ADI 3.106 ED, Rel. Min. Luiz Fux, Tribunal Pleno, DJe 13.08.2015).
} 
Inconstitucionalidade. Seguridade social. Servidor público. Vencimentos. Proventos de aposentadoria e pensões. Sujeição à incidência de contribuição previdenciária. Ofensa a direito adquirido no ato de aposentadoria. [...] Noutras palavras, não há, em nosso ordenamento, nenhuma norma jurídica válida que, como efeito específico do fato jurídico da aposentadoria, lhe imunize os proventos e as pensões, de modo absoluto, à tributação de ordem constitucional, qualquer que seja a modalidade do tributo eleito, donde não haver, a respeito, direito adquirido com o aposentamento. (ADI 3.128/DF, Rel. Min. Ellen Gracie, Tribunal Pleno, DJe 18.02.2005).

Pois bem, cabe salientar neste ponto que o grande problema foi a violação da segurança jurídica para os servidores que estavam próximos de alcançar o direito de pleitear tais benefícios e tiveram que se enquadrar nas regras de transição. Ocorre que o artigo $6^{\circ}$ dessa EC n. 41/2003 garantiu a integralidade e a paridade dos proventos de aposentadoria apenas para os servidores que ingressaram no serviço púbico até a promulgação da EC.

De modo geral, os servidores que ainda não tinham alcançado todos os requisitos necessários para a aposentadoria sofreram redução no valor das pensões e dos proventos de aposentadoria, bem como ganharam mais regras e condições (como o acréscimo dos requisitos de idade mínima) para se aposentarem. Eles ingressaram no serviço público e iniciaram o recolhimento normalmente das contribuições previdenciárias; mas, no decorrer do percurso, antes de fazerem jus ao benefício, sofreram novas regras prejudiciais para suas aposentadorias sob a justificativa do pálio do equilíbrio financeiro do governo (fundamentação, como se percebe, externa ao sistema normativo).

Percebe-se, com isso, evidente desconfiança ocasionada pela perda da boa-fé na norma jurídica, que antes garantia direito à uma forma de aposentadoria e agora retirou essa garantia dos servidores que estavam quase fazendo jus a pleiteá-la. Na esteira dessas razões, apesar do que dizem os críticos ao positivismo de Hans Kelsen, essas jurisprudências demonstram claramente como os cidadãos são diariamente usurpados da segurança jurídica e da confiança que deveriam ter no sistema normativo sob pretextos que não pertencem ao âmbito do Direito.

\section{CONSIDERAÇÕES FINAIS}


A interpretação sistêmica mostrou ser uma peça essencial para as atividades do magistrado e o princípio da segurança jurídica, respaldado pelo princípio da legalidade, traz em seu bojo toda uma esfera de parâmetros que devem ser observados com bom senso por qualquer autoridade operadora do direito. É preciso atingir equilíbrio nesta relação. Deve haver limite para esse subjetivismo decisório ou, do contrário, a segurança jurídica de qualquer cidadão continuará totalmente comprometida.

Todos os pontos tratados neste estudo apontam que a influência de fatores externos (juridicamente não-justificáveis por meio das regras jurídicas), não deve ser absorvida sob o pressuposto de se aplicar princípios jurídicos. Com isso, o sincretismo metodológico não pode servir como lastro para integrar argumentos externos ao âmbito jurídico.

Assim, a "Teoria da Katchanga" de Lênio Streck foi destrinchada para demonstrar, por metáfora, como a volatilidade da jurisprudência da Suprema Corte (e, consequentemente, das demais instâncias) causa uma ruptura na moldura kelseniana e gera insegurança jurídica aos cidadãos brasileiros.

Com efeito, a falta de limites e parâmetros soma-se ao livre convencimento do magistrado e ocasiona incoerências, decisões insustentáveis e insegurança para os jogadores da "Katchanga" judicial do Poder Judiciário. O ato de movimentar o ente estatal para deliberar sobre um ponto consolidado na doutrina, jurisprudência ou legislação não é garantia que a decisão ministerial corra no mesmo sentido.

Hoje em dia, o contribuinte instaura um processo judicial para reaver os seus direitos e não sabe se o STF utilizará de fundamentos dentro do âmbito do Direito ou pertencentes à economia, política ou sociedade para justificar alguma repentina mudança de entendimento sobre uma determinada norma.

Dessa maneira, somente com a limitação do subjetivismo dos ministros do STF e do sincretismo metodológico é que o cidadão brasileiro poderá, de fato, utilizar os meios legais permitidos para mover a máquina judiciária sem se aventurar numa seara de insegurança, cuja vontade do ministro da Corte Supremo ainda é o cerne que determina se um ato pode ou não ser considerado como válido.

\section{REFERÊNCIAS}


ÁVILA, Humberto Bergmann. Segurança Jurídica: entre permanência, mudança e realização no direito tributário. 2. ed. São Paulo: Malheiros Editores, 2012a.

ÁVILA, Humberto Bergmann. Sistema Constitucional Tributário. 5. ed. São Paulo: Saraiva, 2012b.

BARACHO JÚNIOR, José Alfredo de Oliveira. Responsabilidade civil por dano ao meio ambiente. Belo Horizonte: Del Rey, 2000.

BERNARDES, Flávio Couto. O aspecto procedimental como elemento da norma jurídica tributária e seus reflexos na formação do título executivo. 2006. $463 \mathrm{f}$. Tese (Doutorado) Curso de Doutorado da Faculdade de Direito, Universidade Federal de Minas Gerais, Belo Horizonte, 2006.

BARRAL, Welber Oliveira. Metodologia da Pesquisa Jurídica. 2. ed. Florianópolis: Fundação Boiteux, 2003, 208 p.

BRASIL. Lei n. 13.105 (2015). Código de Processo Civil. Disponível em: http://www.planalto.gov.br/ccivil_03/_ato2015-2018/2015/lei/113105.htm. Acesso em 21 de novembro. 2019.

BRASIL. Supremo Tribunal Federal. Ação Cautelar/QO 1.886. Rel. Min. Celso de Mello Segunda Turma, Diário de Justiça Eletrônico, Brasília, 07.11.2008. Disponível em: http://www.stf.jus.br/portal/processo/verProcessoAndamento.asp?numero=1886\&classe=AC\&ori gem $=$ AP\&recurso=0\&tipoJulgamento=QO. Acesso em 21 de novembro. 2019.

. ADI 3.106 ED. Rel. Min. Luiz Fux - Tribunal Pleno, Diário de Justiça Eletrônico, Brasília, 13.08.2015. Disponível em:

http://www.stf.jus.br/portal/diarioJustica/verDiarioProcesso.asp?numDj=158\&dataPublicacaoDj= 13/08/2015\&incidente $=4044483 \&$ codCapitulo $=5 \&$ numMateria $=108 \&$ codMateria $=1$. Acesso em 21 de novembro. 2019.

Recurso Extraordinário 350.446. Rel. Min. Nelson Jobim - Tribunal Pleno, Diário de Justiça Eletrônico, Brasília, 18.12.2002. Disponível em:

http://stf.jus.br/portal/processo/verProcessoAndamento.asp?incidente=2040293. Acesso em $21 \mathrm{de}$ novembro. 2019.

Recurso Extraordinário 370.682. Rel. Min. Ilmar Galvão - Tribunal Pleno, Diário de Justiça Eletrônico, Brasília, 25.06.2007. Disponível em: http://www.stf.jus.br/portal/jurisprudencia/listarJurisprudencia.asp?s1=\%28370682\%2ENUME\% 2E+OU+370682\%2EACMS\%2E\%29\&base=baseAcordaos\&url=http://tinyurl.com/zwpefs7. Acesso em 21 de novembro. 2019.

BRÊTAS, Ronaldo C. Dias. Processo Constitucional e Estado Democrático de Direito. 2. ed. Belo Horizonte: Del Rey, 2012. 196 p. 
CARVALHO, Paulo de Barros. Enunciados, normas e valores jurídicos tributários. Revista de direito tributário. São Paulo, n. 69, 1996.

COÊLHO, Sacha Calmon Navarro. Teoria geral do tributo, da interpretação e da exoneração tributária (o significado do art. 116, parágrafo único do CTN). 3. ed. São Paulo: Dialética, 2003.

CRUZ, Álvaro Ricardo de Souza. Jurisdição Constitucional Democrática. Belo Horizonte: Del Rey, 2004.

.Prefácio. In: CUNHA, Ricarlos Almagro Vitoriano. Segurança jurídica e crise no Direito. Belo Horizonte: Arraes Editores, 2012.

DE OLIVEIRA, Júlio Aguiar. Para que serve a teoria do direito? Texto produzido a partir da palestra proferida, em 10 de maio de 2005, no Seminário "Para que serve a Teoria do Direito", realizado pelo Programa de Pós-Graduação em Direito da PUC Minas, de 09 a 13 de maio de 2005. Disponível em:

http://www.hottopos.com/videtur30/julio2.htm. Acesso em 21 de novembro. 2019.

DERZI, Misabel Abreu Machado. Construindo o Direito Tributário na Constituição: uma análise da obra do ministro Carlos Velloso. Belo Horizonte: Del Rey, 2004.

DERZI, Misabel Abreu Machado. Dos princípios gerais do Direito Tributário. In: Tratado del derecho tributário. Lima, 2003.

FABRETTI, Láudio Camargo. Código tributário nacional comentado. 6. ed. São Paulo: Atlas, 2005.

FARIA, Edimur Ferreira de. Curso de Direito Administrativo Positivo. 8. ed. rev. ampl. Belo Horizonte: Fórum, 2015.

FOSSATI, Gustavo. Planejamento tributário e interpretação econômica. Porto Alegre: Livraria do Advogado Ed., 2006. 149 p.

GODOI, Marciano Seabra de. Uma proposta de compreensão e controle dos limites da elisão fiscal no direito brasileiro - estudo de casos. In: Douglas Yamashita. (Org.). Planejamento tributário à luz da jurisprudência. São Paulo: LEX, 2007, p. 237-288.

GONÇALVES, Jair. Herança jurídica de Hans Kelsen. Campo Grande: UCDB, 2001, 184 p.

GRECO, Marco Aurélio. Planejamento tributário. São Paulo: Dialética, 2004.

HUCK, Hermes Marcelo. Evasão e elisão: rotas nacionais e internacionais. 10. ed. São Paulo: Saraiva, 1997. 346 p. 
KELSEN, Hans. A justiça e o Direito natural. João Baptista Machado (Trad.). Coimbra: Armênio Amado, 1963.

Teoria geral do Direito e do Estado. Luís Carlos Borges (Trad.). 2. ed. São Paulo: Martins Fontes, 1992. 1998.

. Teoria pura do direito. João Baptista Machado (Trad.). São Paulo: Martins Fontes,

LUHMANN, Niklas. A improbabilidade da comunicação. Lisboa: Vega, 2006.

. The autopoiesis of Social Systems. In GEYER, F.; ZOUWEN, (Org.). Sociocybernetic paradoxes. London, 1986.

MACÊDO, Lucas Buril. Os precedentes judiciais, a criatividade não reconhecida e a esquizofrenia jurisprudencial. Revista Justificando. 24 de abril de 2015, 8h00. Disponível em: http://justificando.cartacapital.com.br/2015/04/24/os-precedentes-judiciais-a-criatividade-naoreconhecida-e-a-esquizofrenia-jurisprudencial/. Acesso em 21 de novembro. 2019.

STRECK, Lênio Luiz. A Katchanga e o bullying interpretativo no Brasil. Revista Consultor Jurídico. 28 de junho de 2012, 8h00. Disponível em: https://www.conjur.com.br/2012-jun28/senso-incomum-katchanga-bullying-interpretativo-brasil. Acesso em 21 de novembro. 2019.

STRECK, Lênio Luiz; LIMA, Martônio; OLIVEIRA, Marcelo Andrade. A nova perspectiva do Supremo Tribunal Federal sobre o controle difuso: mutação constitucional e limites da legitimidade da jurisdição constitucional. Revista do Programa de Mestrado em Ciência Jurídica da Fundinopi. Paraná: UENP, 2018, p. 45-68.

STRECK, Lenio Luiz. O que é isto - decido conforme minha consciência? 5. ed. Porto Alegre: Livraria do Advogado, 2015.

THEODORO JÚNIOR, Humberto. O papel da jurisprudência no novo Código de Processo Civil. In: GAIO JÚNIOR, Antônio Pereira; CÂMARA, Alexandre Freitas (Coord.). Código de Processo Civil: novas reflexões e perspectivas - atualizado com a Lei n. 13.256, de 04 de fevereiro de 2016. Belo Horizonte: Del Rey, 2016, 248 p.

TRIVISONNO, Alexandre Travessoni Gomes. O que significa "a injustiça extrema não é direito"? Crítica e reconstrução do argumento da injustiça no não-positivismo inclusivo de Robert Alexy. Espaço Jurídico Journal of Law [EJJL]. Joaçaba: Unoesc, v. 16, n. 3, p. 97-122, Edição Especial 2015.

TORRES, Heleno Taveira. Direito constitucional tributário e segurança jurídica: metódica da segurança jurídica do Sistema Constitucional Tributário. 2. ed. São Paulo: Editora Revista dos Tribunais, 2012.

XAVIER, Alberto. Os princípios da legalidade e da tipicidade da tributação. Revista dos tribunais. São Paulo, 1978. 
$175 \mathrm{p}$.

. Tipicidade da tributação, simulação e norma antielisiva. São Paulo: Dialética, 2001.

THE SEMANTIC DENSITY OF KATCHANGA AND THE CRISIS OF JURIDICITY IN

BRAZIL

\begin{abstract}
The Kelsenian framework proposes that the normative interpretation must be systemic and the legal order must be coherent for that exist security in the social relations. The interpretative reasoning to correctly apply a norm must find support in the ordering in which it is inserted. Indeed, the history of the "Katchanga Theory" serves to metaphorize the current legal dogma of the Brazilian Supreme Court, symbolizing how forensic decisions and the understanding of the ministers ("Real Katchanga") change the rules of the game and cause large insecurity to the citizens.
\end{abstract}

Keywords: Legal security. Katchanga Theory. Jurisprudence. 